\title{
A MEMS-Based Fuel Cell for Microscale Energy Conversion
}

\author{
J. Morse, A. Jankowski
}

February 1, 2002

U.S. Department of Energy

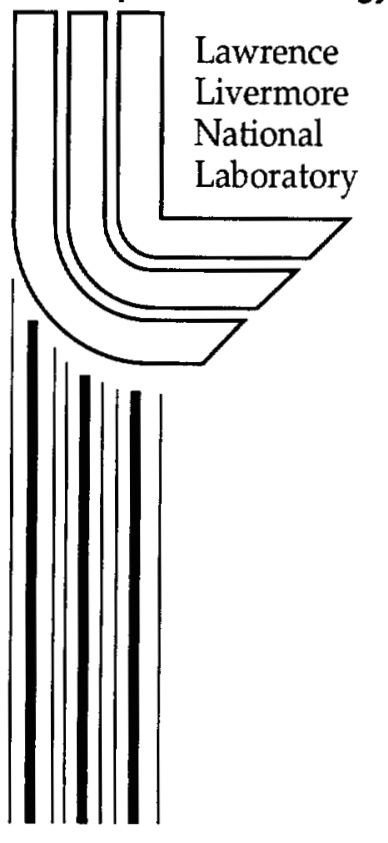




\section{DISCLAIMER}

This document was prepared as an account of work sponsored by an agency of the United States Government. Neither the United States Government nor the University of California nor any of their employees, makes any warranty, express or implied, or assumes any legal liability or responsibility for the accuracy, completeness, or usefulness of any information, apparatus, product, or process disclosed, or represents that its use would not infringe privately owned rights. Reference herein to any specific commercial product, process, or service by trade name, trademark, manufacturer, or otherwise, does not necessarily constitute or imply its endorsement, recommendation, or favoring by the United States Government or the University of California. The views and opinions of authors expressed herein do not necessarily state or reflect those of the United States Government or the University of California, and shall not be used for advertising or product endorsement purposes.

This work was performed under the auspices of the U.S. Department of Energy by the University of California, Lawrence Livermore National Laboratory under Contract No. W-7405-Eng-48.

This report has been reproduced directly from the best available copy.

Available electronically at http://www.doc.gov/bridge

Available for a processing fee to U.S. Department of Energy

And its contractors in paper from

U.S. Department of Energy

Office of Scientific and Technical Information P.O. Box 62

Oak Ridge, TN 37831-0062

Telephone: (865) 576-8401

Facsimile: (865) 576-5728

E-mail: reports@adonis.osti.gov

Available for the sale to the public from

U.S. Department of Commerce

National Technical Information Service

5285 Port Royal Road

Springfield, VA 22161

Telephone: (800) 553-6847

Facsimile: (703) 605-6900

E-mail: orders@ntis.fedworld.gov

Online ordering: http://www.ntis.gov/ordering.htm

OR

Lawrence Livermore National Laboratory

Technical Information Department's Digital Library

http://www.llnl.gov/tid/Library.html 


\title{
A MEMS-Based Fuel Cell for Microscale Energy Conversion
}

\author{
Jeffrey Morse and Alan Jankowski
}

\begin{abstract}
A novel approach to realize a miniature fuel cell power source by combining thin film solid-oxide or proton exchange membrane electrolyte-electrode materials with MEMS techniques to integrate a fuel cell stack monolithically on a manifolded host structure is described. This architecture enable a scalable, portable fuel cell power source system for a broad range of applications having power requirements in the $<1 \mathrm{~W}$ to $>10 \mathrm{~W}$ regime. The MEMS approach offers a direct means to integrate the fuel cell stack with required manifolding and fuel delivery system, while providing the means to control the performance of the power source for specific applications. Results describing the fabrication, integration, and testing of MEMS-based fuel cells are presented below.
\end{abstract}

\section{Introduction}

The problem of portable power sources remains critical for all aspects of the military, weapons testing, and intelligence community. While batteries have become a minor hindrance in the case of consumer portable electronics, they are simply not adequate for the advanced applications of remote reconnaissance, intelligence and telemetry. New power sources are required, with many of these having specific performance criteria for the direct application. A lighter weight, longer lasting power source provides new functionality to missions of all kinds, promising long term cost benefits to all government agencies, enabling new levels of safety and security for personnel in the field, along with general national security.

Miniature fuel cells have recently experienced renewed interest for applications in portable power generation. Fuel cells store energy as fuel rather than as an integrated part of the system, which is the case with batteries. Therefore, fuel cells can potentially exhibit significantly higher energy densities, as illustrated in Figure 1, depending on the type of fuel being utilized. While this has been demonstrated for higher power portable applications (50-500W), effective scaling of fuel cell systems has not been demonstrated for low power applications $(<1-50 \mathrm{~W})$. Present applications in portable power include the full range of consumer electronics, e.g. cell phones, laptop computers, video camcorders, and radios. New applications in portable power span the range of power consumption from micro, as in long duration sensors and remote communication devices, to macro, as in light weight packages for use in the field.

Power remains one of the key limitations for portable electronics, sensors, and systems being developed for programs such as NAI and DNT/Weapons. For applications such as Flight Test, or Counterterrorism intelligence gathering and surveillance, individual or networks of sensors are fielded having increasing levels of data gathering, processing, and communication transmitting capabilities. The batteries utilized to power these systems allow only short 
durations of operation, or severely limit the performance of the electronics, and typically must be designed to the specifications of the power source, which is less than desirable. A miniature fuel cell power source alleviates these problems through a flexible, engineered approach. Storage of available energy in the form of fuel provides significant advantages in comparison to competitive battery technologies. To achieve further increases in the energy density of the fuel cell, an advanced metal hydride can be incorporated to store hydrogen fuel, or direct methanol fuel cells may provide an improvement of 3-5 times over batteries. The energy potential of hydrocarbon fuels can be more completely exploited through a catalytic reaction device'. Such a device can be packaged directly with the MEMS-Based Thin-film Fuel Cell ${ }^{2}$, providing and integrated solution offering $>10 \mathrm{x}$ improvement over battery technologies.

\section{Scope}

The work has investigated the technical issues and concerns associated with developing an integrated MEMS-based fuel cell power source. The targeted power output is in the the 0.1 to $0.5 \mathrm{~W}$ range, with possible scaling up to $>10.0 \mathrm{~W}$ for specified applications. This power source has the potential to exhibit longer mission durations than existing battery technologies, and be designed for specific implementation in wireless remote sensing applications. Through the combination of thin films materials, microfabrication, and silicon micromachining, a materials and fuel flexible power source is realized, as illustrated in Figure 2. This effort represents a completely new approach to fuel cell miniaturization, and opens up a new range of applications for fuel cells providing power for autonomous sensor networks being developed for national security requirements. The MEMS-based fuel cell offers advantages in terms of manufacturability, fuel flexibility, reduced temperature of operation, and higher specific energy in comparison to other fuel cell and battery technologies. A further advantage is the direct scalability of this approach through stacking of individual fuel cell modules, achieved through micromachined packaging methods ${ }^{3}$. This enables a wide range of power requirements to be addressed with a common module design.

\section{MEMS-Based Fuel Cell Architecture}

This effort has demonstrated the viability of thin film MEMS-based fuel cell technologies for portable power sources. The fabrication and initial operation of both solid-oxide and proton exchange membrane (PEM) electrolytes in fuel cells monolithically integrated on silicon substrates having micromachined manifold systems has been demonstrated. In developing the fabrication process we have addressed several issues associated with the integration and performance of a fuel cell stack, micromachined fuel manifold and flow field structure. The MEMS-based fuel cell architecture is shown in Figure 3. The fuel cell electrode-electrolyteelectrode structure is deposited and patterned on the silicon host structure to define the cell active area, and form the electrical leads for the anode and cathode. Various techniques have been utilized to accomplish this, including vacuum deposition, solgel, and spin cast approaches. Next the silicon host structure has been micromachined to form the manifold structure for fuel flow to 


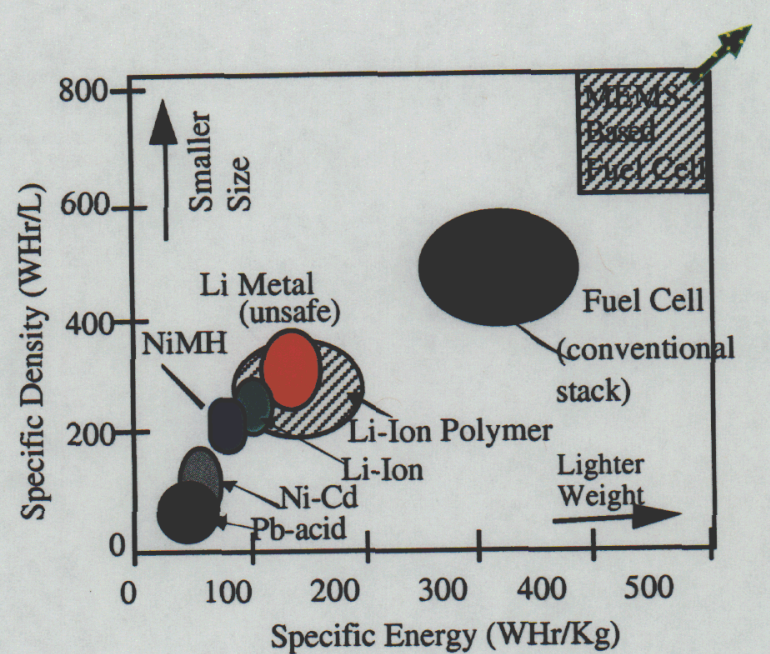

Figure 1: Comparison of specific energy of MEMS-based fuel cell with various battery technologies.

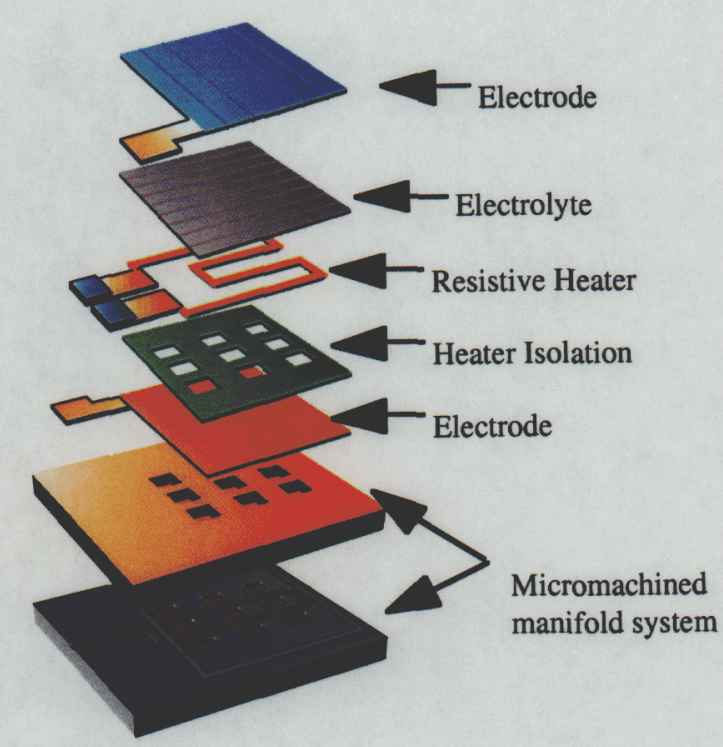

Figure 2: Schematic illustration of MEMS-based fuel cell concept.

the anode. The cathode remains air breathing, therefore a manifold is not necessary unless stacking the cells. At this point the electrode-electrolyte assembly forms a free standing membrane on the surface of the host structure. Further augmentations have been incorporated to form porous electrode structures. Figure 4 illustrates an example of a porous $\mathrm{Ni}$ anode formed by photolithographic patterning and etching the $\mathrm{Ni}$ before coating with the electrolyte layer. Figure 5 illustrates the anisotropically etched manifold structure through the silicon host structure, with the free standing electrode-electrolyte membrane.
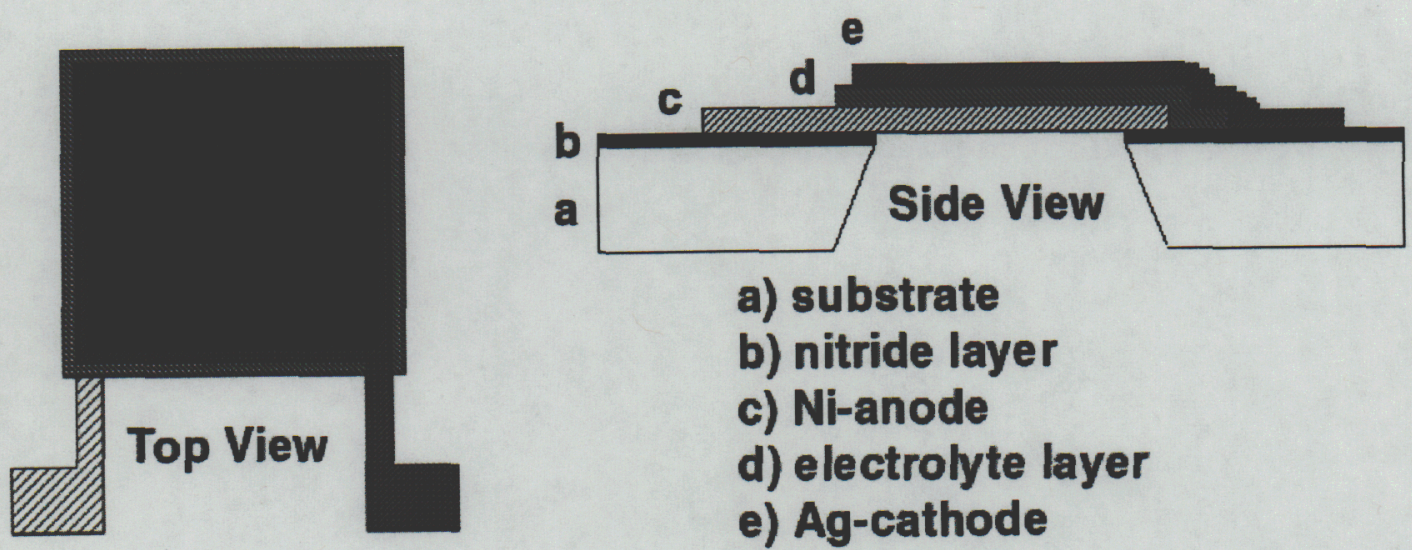
a) substrate
b) nitride layer
c) Ni-anode
d) electrolyte layer
e) Ag-cathode

Figure 3: A schematic of the thin film, solid-oxide fuel cell design for micro to macro power generation. 


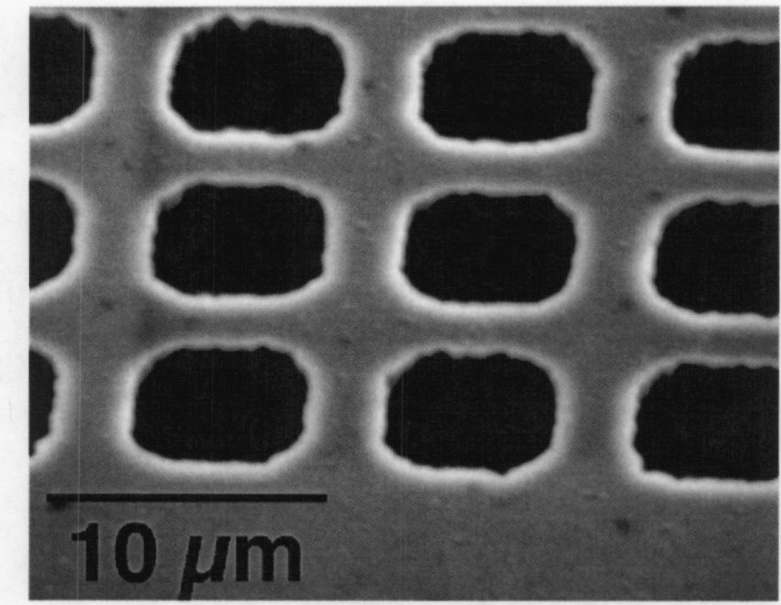

Figure 4: A top view of the $0.5 \mu \mathrm{m}$ thick $\mathrm{Ni}$ anode layer as imaged using scanning electron microscopy at higher magnification.



Figure 5: A bottom view of the Ni anode layer deposited on the substrate platform as imaged using scanning electron microscopy.

Porous electrode structures have been formed in the cathode layer by a similar means. This allows the rapid diffusion of fuel and oxidant through the electrode structures to the electrolyte interface, as well as the exhaust of reaction byproducts (water). The MEMS architecture allows a materials and fuel flexible platform for fuel cell power generation. The inherent scalability further allows a range of power levels to addressed for various applications and custom requirements.

\section{Gas Diffusion Electrodes and Support Structure}

For many applications a more robust gas diffusion electrode support structure is required. In this case, a higher power per unit surface area of the support structure is necessary, therefore the manifold must deliver fuel to a large fraction of the available host structure surface. This is illustrated schematically in Fig 6 in which a macroscale $(>500 \mu \mathrm{m})$ manifold structure is formed on the backside of the silicon substrate, followed by the formation of a high density array of microscale pores $(<10 \mu \mathrm{m})$ in the top surface which extend through to the manifold. The anode coating is then deposited directly on the microporous surface, subsequently closing off the pores with the dense electrolyte coating, followed by a porous cathode coating to complete the cell. This particular architecture provides more flexibility in optimizing the catalyst materials at the electrolyte interface, and is more directly integrable with fuel processing elements.

The main objective of the advance gas diffusion electrode support design is to increase the power density of the thin film fuel cells by extending the total surface area to which fuel is manifolded. This has been achieved through novel integration processes which produce microporous manifold support structures with a nanoporous host structure on which thin film 


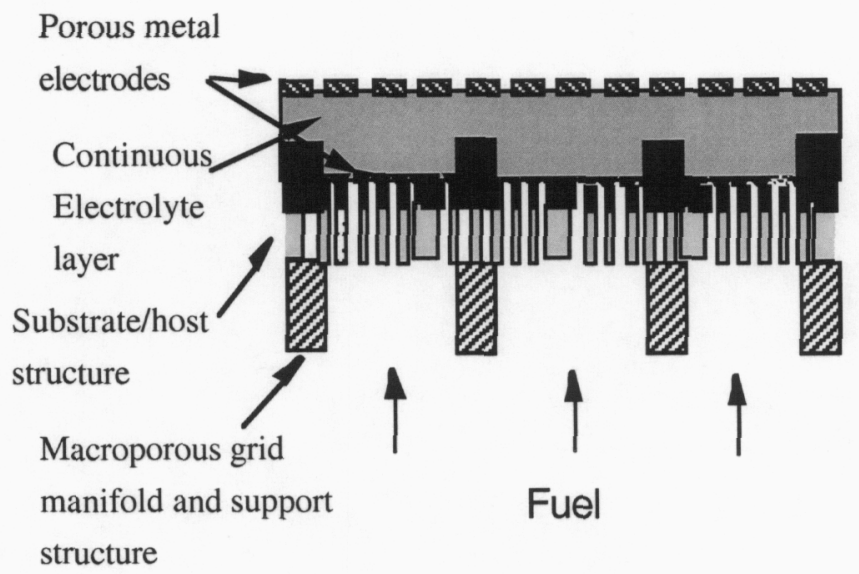

Figure 6: Schematic illustration of cross section of microporous gas diffusion electrode support structure for thin film fuel cell device.

electrodes are formed. Figure 7 and 8 are scanning electron micrographs illustrating the gas diffusion electrode support structures were fabricated in silicon substrates using deep anisotropic etch techniques. These structures will enable a highly porous host structure for gas diffusion to the anode, while retaining the necessary mechanical strength to withstand high temperature swings and pressure gradients.

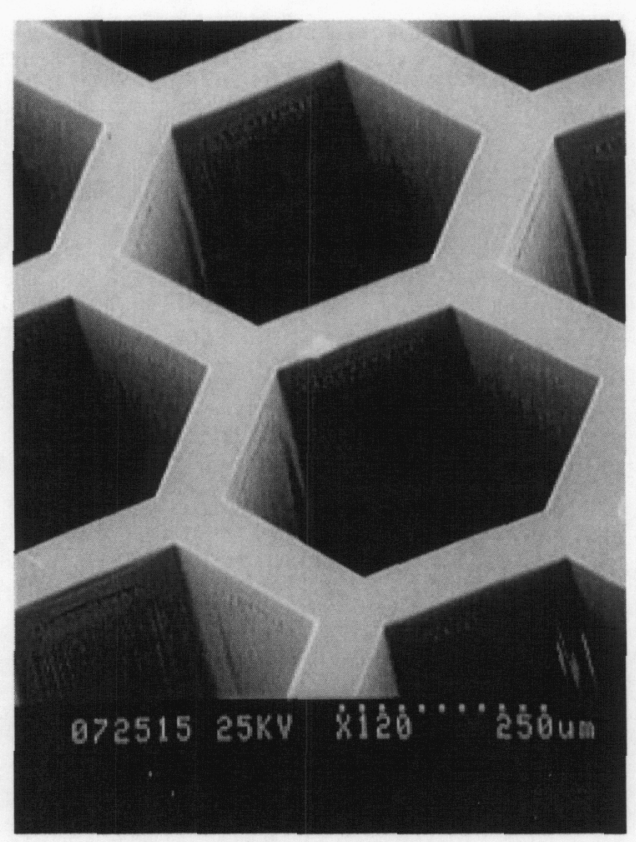

Figure 7: Manifold structures etched in silicon host structure by deep anisotropic etching from the backside.

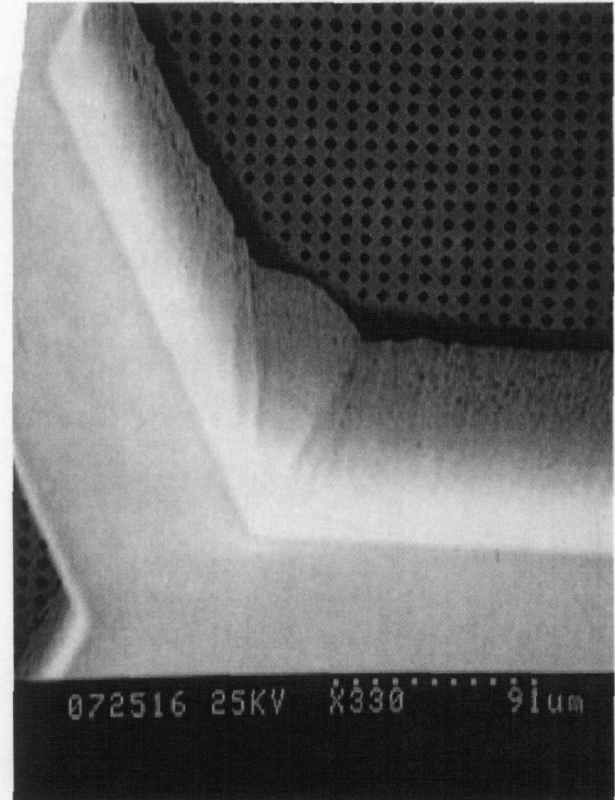

Figure 8: Microporous gas diffusion electrode support formed by deep anisotropic etching from the frontside. 
The electrode layers should enable combination of the reactive gases and be conductive to transport the electric current. Thus a porous morphology is desirable for both electrodes. Standard lithography procedures yield an anode structure (imaged using scanning electron microscopy) as shown in Figure 4 above. The fuel cell output is enhanced through maximizing the contact area between the electrode and electrolyte. Thus further reducing the electrode pore size from five to ten micrometers may enhance the electrical performance and additionally, the mechanical strength of the support electrode. A method is developed to deposit an electrode with micron-scale porosity. A metallic sponge can be produced by appropriately controlling the sputtering conditions. By combining a moderate sputter gas pressure and an elevated substrate temperature, a sponge-like morphology is produced with micron-scaled porosity. The moderate sputter gas pressure creates a range of incident angles for deposition and the elevated temperature promotes a faceted crystalline growth. The result is the three-dimensional structure as seen for a nickel anode and silver cathode in Figures 9 and 10, respectively.

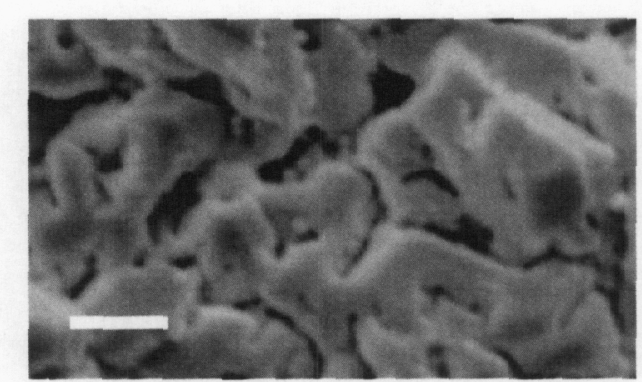

Fig. 9: The top view of a nickel anode produced at high temperature and sputter gas pressure. $\mathrm{Bar}=0.5$ microns.

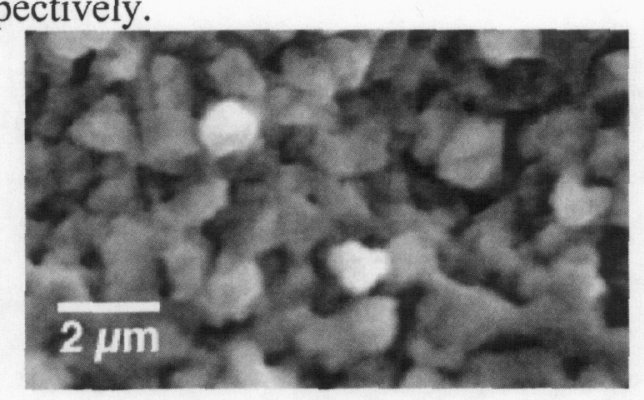

Fig. 10: The top view of a silver cathode produced from sputter deposition at high temperature and gas pressure.

\section{Thin Film Fuel Cells}

Solid oxide fuel cells (SOFCs) are typically made using components from bulk ceramic powder processing in combination with a synthesis approach of layering the cermet electrode with the electrolyte layer. SOFCs can be operated at temperatures as low as $400^{\circ} \mathrm{C}$ or in excess of $1000^{\circ} \mathrm{C}$ for high performance. Proton exchange membrane fuel cells (PEMFCs) are often made as a laminate or spin cast polymer electrolyte and typically operate below $125^{\circ} \mathrm{C}$. In each application, coatings in thin or thick film form can be used for processing the electrolyte as well as the electrodes. The use of vapor deposition methods such as sputtering readily accesses a wide range of target compositions to form the electrolyte or electrode layers that will enhance cell performance. Further incorporation of precision catalyst loading within the electrode structure further enhances performance of the fuel cell while maintaining low cost processes. 


\section{Solid Oxide Electrolytes}

The synthesis of a thin film solid oxide based electrolyte fuel cell stack has been demonstrated. The thin film solid oxide fuel cell (TFSOFC) stack was formed using physical vapor deposition (PVD) techniques. The host substrate used was a silicon wafer covered by a thin layer of silicon nitride. A layer of nickel was first deposited, followed by a layer of yttriastablized zirconia (YSZ). The conditions during the deposition were adjusted in order to achieve smooth, dense, continuous films, thus avoiding pinhole formation, which could result in electrical shorting through the electrolyte layer. This enables the electrolyte layer to be on the order of 1-2 $\mu \mathrm{m}$ thick rather than typical thicknesses on the order of $>10 \mu \mathrm{m}$ for bulk solid oxide fuel cells. By thinning the electrolyte layer, resistive losses are significantly lower, and the fuel cell operates at much lower temperatures. A silver electrode layer is deposited on top of the YSZ layer. The deposition conditions of this film are adjusted to create a porous structure so that oxygen can readily diffuse to the electrolyte interface. An example of thin film SOFC devices monolithically integrated on a silicon substrate is illustrated in Figure 11. These devices have a series of free standing membranes $(2 \mathrm{~mm} \times 2 \mathrm{~mm})$. The structure also incorporates a resistive heating element to directly heat the electrode-electrolyte stack to the operating temperature without heating the entire silicon host structure. Figure 12 shows a cross section scanning electron micrograph of the deposited SOFC layers.

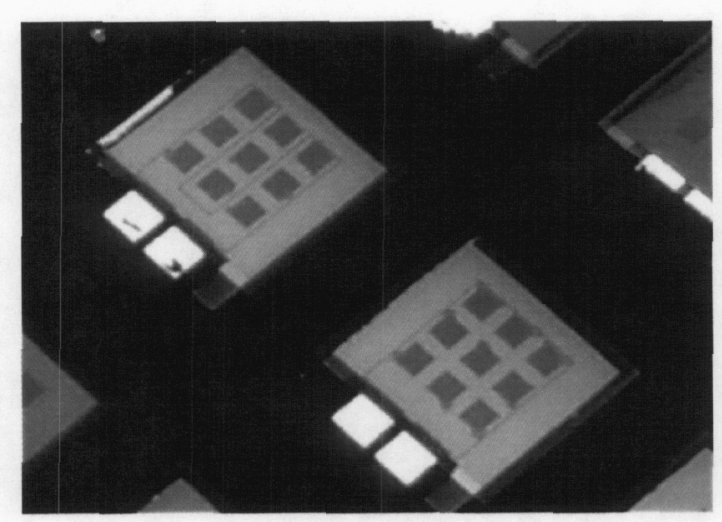

Figure 11: Top view of thin film SOFC devices fabricated on silicon substrates.

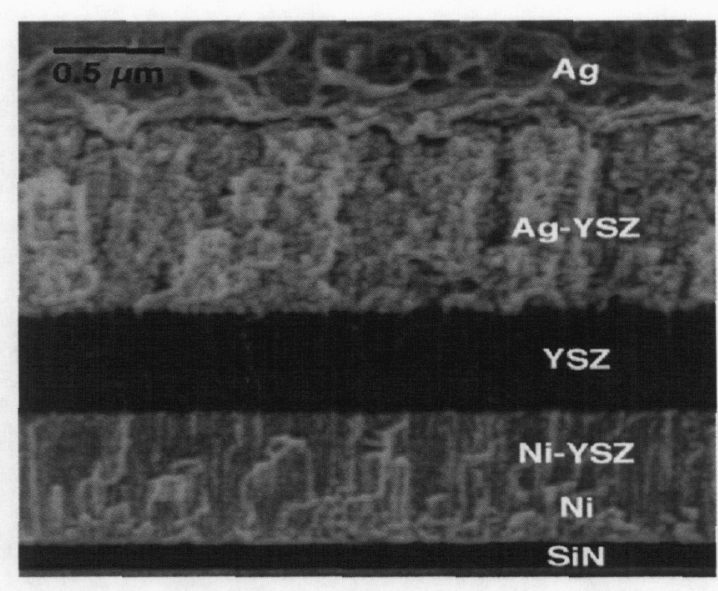

Figure 12: Cross sectional scanning electron micrograph of thin film SOFC electrode-electrolyte layers.

From Figure 11, integrated circuit type microfabrication processes are used to pattern electrode contacts, as well as to form a resistive heater element within the stack structure. The stack is subsequently formed into a free standing membrane by selective etching of the substrate. This approach provides an effective means to form efficient fuel cell stack and electrode structures monolithically, and distribute fuel to the entire stack without the need for bulky complex manifolding. Furthermore, since the stack is now only a small percentage of the mass of 
the entire structure, appropriate thermal design of the fuel cell device, package, and resistive heating elements will allow efficient, low power heating of the stack.

Thin film solid oxide fuel cell (tfsofc) structures have been fabricated combining sputter deposition of electrode-electrolyte films onto silicon substrate host structures, and anisotropic etching of silicon to form a fuel flow manifold through the silicon to the anode layer. A manifolded host structure was formed in silicon by first depositing a layer of low stress CVD nitride $(2000 \AA)$. The backside of the wafer was lithographically patterned to create openings in the nitride film. A CF $/ \mathrm{O}_{2}$ plasma etch was used to open the nitride, followed by a $\mathrm{KOH}$ etch at $80^{\circ} \mathrm{C}(\sim 1 \mu \mathrm{m} / \mathrm{min}$ etch rate) to open the silicon up to the frontside, leaving a $2 \mathrm{~mm} \times 2 \mathrm{~mm}$ nitride membrane window.

Shadow masking was used to pattern sputter deposited films aligned over the nitride membrane windows. The first layer deposited is a $5000 \AA$ Ni layer, followed by a $2 \mu \mathrm{m}$ Yttriastablized Zirconia (YSZ) layer, and a $5000 \AA \mathrm{Ag}$ cathode layer. Previous imaging of sputtered films having similar deposition parameters showed columnar structure of the metal films, with relatively dense electrolyte films (Fig 12).

Device testing used a glass tube for fuel feed bonded to the backside of the silicon wafer using a high temperature silver epoxy. Similarly, a glass tube for air feed was compressed on the topside of the silicon wafer. Wires were epoxied to the anode and cathode at the topside, and fed through this tube length. The fixture was then placed in a clamshell furnace and brought to temperature with a $3 \mathrm{sccm}$ flow of dilute $\mathrm{H}_{2}(4 \%)$ flowing into the backside tube. The resulting current-voltage and current-power performance for the cell is shown in Figures 13 and 14 for a range of temperatures. Figure 15 illustrates the actual measured I-V output for the $2 \mathrm{~mm} \times 2 \mathrm{~mm}$ cell.

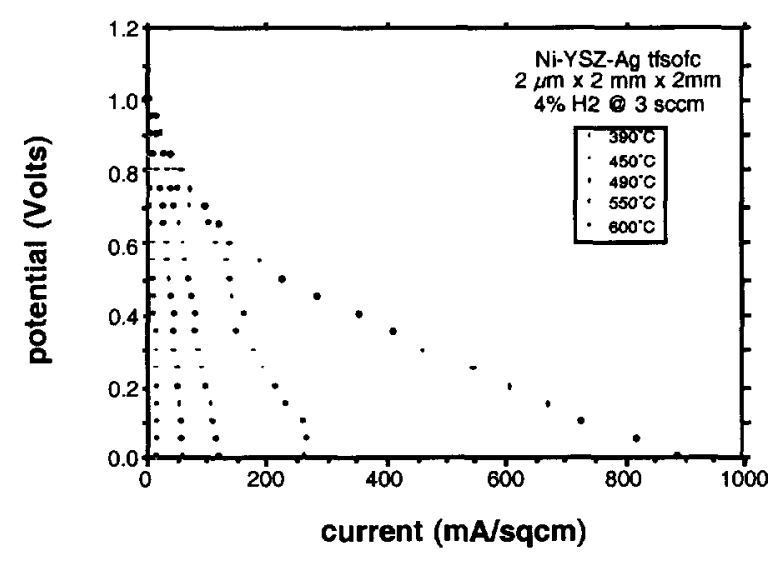

Figure 13: Cell potential vs. current density for TFSOFC with $3 \mathrm{sccm}$ of $4 \% \mathrm{H}_{2}$

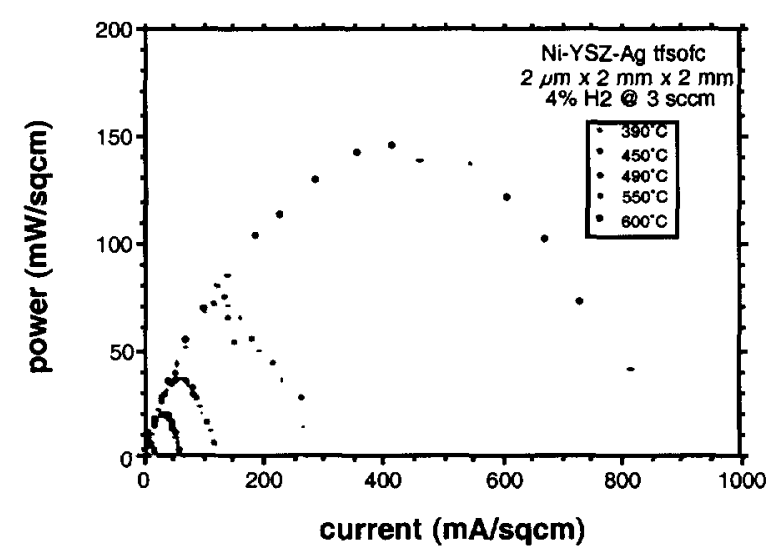

Figure 14: Cell output power vs. current density for TFSOFC with $3 \mathrm{sccm}$ of $4 \% \mathrm{H}_{2}$ 


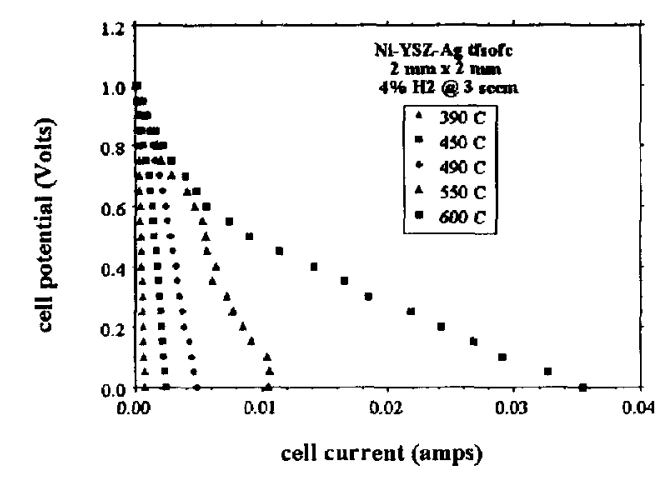

Figure 15: Measured I-V output for $2 \mathrm{~mm} \times 2 \mathrm{~mm}$ SOFC with $4 \%$ dilute hydrogen fuel

\section{MEMS-Based Proton Exchange Membrane Fuel Cells Progress}

Proton exchange membrane (PEM) fuel cells are also being developed as a replacement for batteries in portable electronics. The advantage of PEMFC's is the low operationg temperature $\left(25-90^{\circ} \mathrm{C}\right)$, which simplifies the packaging. The disadvantages include the need for balancing the hydration of the electrolyte membrane. Too little water results in a degradation of the membrane proton conductivity, and too much water results in an excess of water buildup at the cathode, which limits the oxygen reactions at the cathode, additionally degrading cell performance. The issues can be avoided by evaporating or flowing water in the fuel feed, operating the cell at current low densities $\left(50-100 \mathrm{~mA} / \mathrm{cm}^{2}\right)$, and incorporating hydrophobic materials to prevent water buildup at the cathode. The target at this stage is a wireless telecommunication application requiring $100 \mathrm{mAmps}$ of current for a $3 \mathrm{~V}$ supply. Our work at LLNL has focused on a miniaturization approach exploiting MEMS techniques to achieve fuel cell support, manifold and stacking requirements for the power source. Additionally, initial prototypes will utilize a microfluidic package for fuel storage and delivery. While initial fuel utilizes a dilute hydrogen source, direct methanol PEM fuel cells will also be tested. The present studies are targeted to optimize the packaging and operating regime of individual cells prior to proceeding with voltage scaleup through planar monolithic integration, or direct modular stacking. Further, present designs are readily scalable to power levels in the 1-5 Watt range using similar approaches.

\section{MEMS-Based PEM Fuel Cell}

The key development recently demonstrated for the MEMS-based fuel cell is the integrated gas diffusion electrode support structure as previously illustrated. At present, these components are fabricated in silicon through a self-aligned deep anisotropic silicon etch 
procedure. The result is a thin film electrode structure having a very high density of micropore channels over a large surface area. These channels allow diffusion of air and fuel to the respective electrode-catalyst interface at near atmospheric pressures, which with appropriate design will enable the entire fuel surface to actively generate current. The gas diffusion electrodes can also be fabricated in other materials, such as polyimide or thermoplastics, and these designs are presently under development.

The MEMS-based PEM fuel cell designs can utilize either a thin film fuel cell approach in which the anode catalyst is mixed in an ink and cast onto the electrode support, followed by deposition of the electrolyte film. The cathode catalyst/electrode thin films are then deposited to complete the PEM fuel cell. The alternative is to utilize electrolyte membranes, which can be purchased in sheets having thickness in the 2-4 mil range, then use the catalyst inks to bond the gas diffusion electrode supports thereby forming the PEM fuel cell. Both approaches are presently being pursued at LLNL. The final method utilized will be determined by the appropriate reliability, robustness, and scaleup to manufacturability as required for the application.

\section{PEM Fuel Cell Testing}

Recent testing of integrated MEMS-Based fuel cells with the most recent gas diffusion electrode supports has shown key progress towards the goals as stated above. Figure 16 illustrates the output power and voltage vs. current for a cell having $\sim 1 \mathrm{~cm}^{2}$ anode area at a nominal temperature of $89^{\circ} \mathrm{C}$. The fuel used was $4 \%$ dilute wet $\mathrm{H}_{2}$, and a mixture of $20 \% \mathrm{O} 2$ in Ar was flowed to the cathode. The flow rates were $1.5 \mathrm{sccm}$ to the anode and cathode respectively, and a backpressure of 2 psig was applied for the anode feed. Further currentvoltage characteristics of the cell were measured at various temperatures as illustrated in Figure 17 , and short circuit current outputs exceeding $160 \mathrm{~mA}$ were observed for direct air breathing cathodes. (Note: $100 \mathrm{~mA}$ is the limit of the present data acquisition system, which is being upgraded)

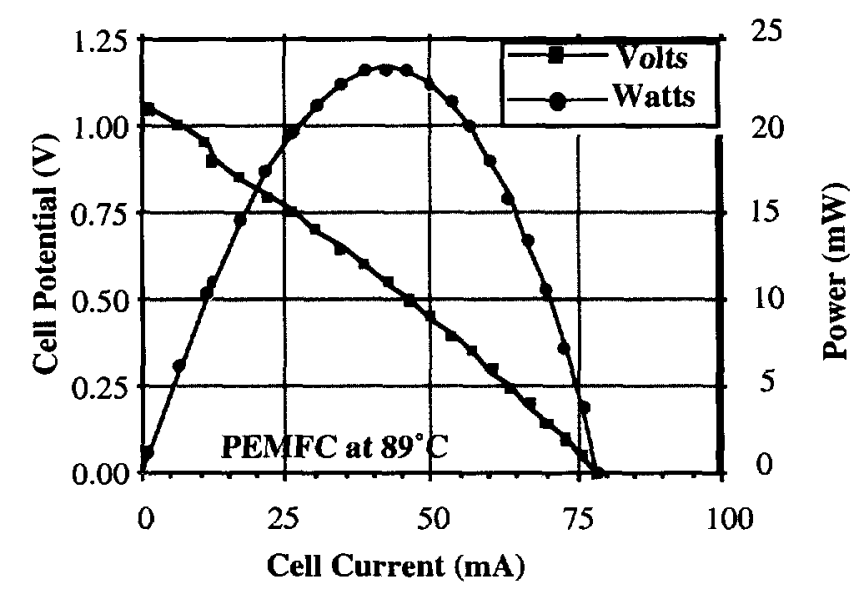

Fig. 16: PEM fuel cell performance with dilute (4\%) wet $\mathrm{H}_{2}$ fuel. 


\section{Fuel Cell Packaging and Test}

Prototype fuel cell packages are presently being developed. The package shown in Fig. 18 incorporates air breathing cathode, integrated resistive heater for internal heating and control, fuel inlet and exhaust, and compression seal for fuel/oxidant isolation. Preliminary evaluation of the package configuration has demonstration heating of the fuel cell to operating temperatures in $<60$ seconds. Further evaluation will include extensive testing of standalone fuel cell power sources with fuel inlet, and resistive heater power input. Subsequent iterations will further evaluate the use of direct methanol fuel, followed by inclusion of flow control elements as necessary for direct applications. Once these technical demonstrations have been completed, the follow-on design would minimize the size and mass of the package structure through incorporation of microfluidic designs and approaches, particularly in the fuel delivery and processing stages.

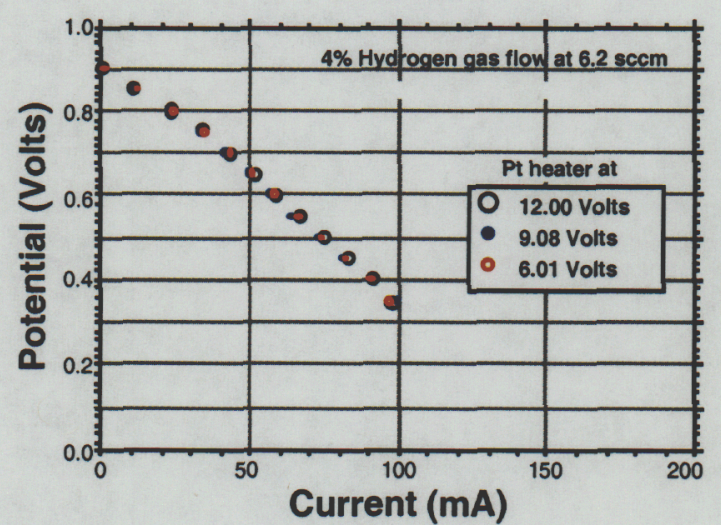

Fig. 17: Current voltage characteristics of PEM fuel cell as a function of temperature.

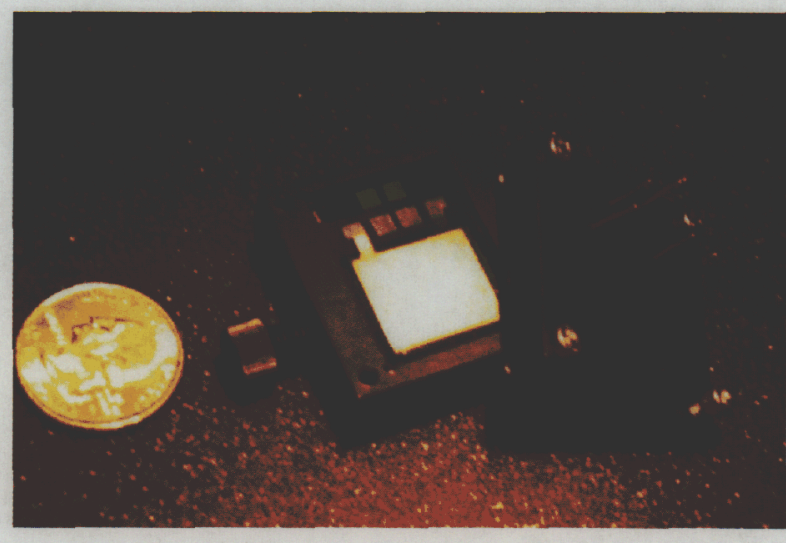

Fig. 18: Prototype fuel cell package

\section{Low Temperature Solid Oxide Electrolyte Materials}

Development has continued on solid oxide electrolyte materials systems which offer operation at low temperatures in comparison to the YSZ electrolyte results presented above. In this approach, Ceria-based electrolytes combined with appropriate anode and cathode catalysts and electrode materials may offer significantly lower operating temperatures $\left(300-450^{\circ} \mathrm{C}\right)$. The thin film approach further offers precise control of these materials at the interface, as well as the structure through the dense electrolyte layers. Additionally, the defect strcutures in the electrolyte layers may be specifically tailored to enhance ionic conduction at lower temperatures.

Figure 19 illustrates a sputter deposited coating of Ceria on the micromachined gas diffusion electrode support structure. In this case, porous $\mathrm{Ni}$ was first coated to close over the 
gas flow pores in the silicon host structure. This was followed by a sputter depositing approximately $9 \mu \mathrm{m}$ of ceria, followed by a porous silver cathode as shown above. The electrolyte coating was deposited sufficiently thick to provide a pinhole free coating over the porous anode structure.

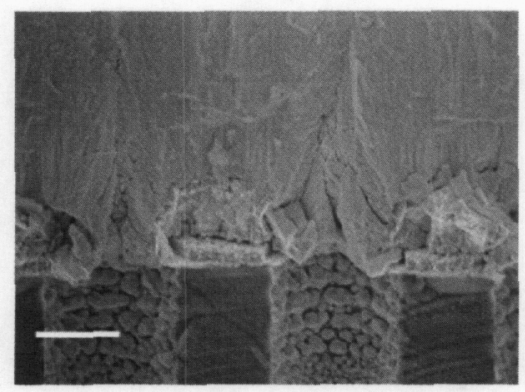

Figure 19. Cross-section image of a sputter-deposited Ceria electrolyte (top) layer on a nickel anode (bottom) layer. The (vertical) micro-channels etched through the silicon to the substrate surface (with $5 \mu \mathrm{m}$ diameter pores) are lined with the residue of a nodular coating from the anode material deposition step. Bar $=3 \mu \mathrm{m}$

\section{Summary}

A materials flexible fuel cell architecture has been demonstrated which enables flow field and manifold structures to be directly integrated with the gas diffusion electrode support structure. Both solid oxide and proton exchange membrane fuel cells have been fabricated and tested. The micromachined, microfluidic architecture offers further levels of integration with catalytic fuel processing and storage components for realization of high energy density, miniature power sources. 


\section{References}

1. IL-10634 Jeffrey D. Morse, Alan Jankowski, A Porous Membrane Catalytic Microreactor, November, 1999.

2. IL-10186 14029 Alan F. Jankowski, Jeffrey D. Morse 9898 13,495, A MEMS-Based Thinfilm Fuel Cell, January 1999.

3. IL-10692 Alan F. Jankowski, Jeffrey D. Morse, Randy Barksdale, Method for fabricating Porous Electrodes for Fuel Cells

4. IL-10672 Alan F. Jankowski, Jeffrey D. Morse, Method for Packaging MEMS-based Fuel Cells

5. A. Jankowski, T. Graff, J. Hayes, and J. Morse, "Testing of Thin-Film SOFCs for Micro to Macro Power Generation", Solid Oxide Fuel Cells VI, ed. S. Singhal and M. Dokiya, Electrochemical Society Proceedings Volume 99-19 (The Electrochemical Society, Pennington, 1999) 932-937, presented at the Joint International Meeting of the Electrochemical Society and the International Society of Electrochemistry, Honolulu, Hawaii, October 18-22, 1999, UCRLJC-134198

6. J. Morse, R. Graff, J. Hayes, and A. Jankowski, "Porous Thin-Film Anode Materials for Solid-Oxide Fuel Cells", New Materials for Batteries and Fuel Cells, ed. D. Doughty, H. Brack, K. Naoi, L. Nazar, Materials Research Society Symposia Proceedings 575 (submitted for publication), presented at the MRS Spring Meeting, San Francisco, California, April 5-9, 1999, UCRL-JC-132472

7. A.F. Jankowski and J.D. Morse, "Thin Film Synthesis of Novel Electrode Materials for SolidOxide Fuel Cells", Materials for Electrochemical Energy Storage and Conversion II, ed. D. Doughty, D. Ginley, B. Scrosati, T. Takamura and Z. Zhang, Materials Research Society Symposia Proceedings 496 (1998) 155-158, presented at the MRS Fall Meeting, Boston, Massachusetts, December 1-5, 1997, UCRL-JC-

8. J.D. Morse and A.F. Jankowski, "A Novel Thin-Film Solid-Oxide Fuel Cell for Microscale Energy Conversion", Microscale \& Mesoscale Energy Systems and Miniature Energy Conversion Devices, ed. M.K. Drost and R.B. Peterson, American Society of Mechanical Engineers Proceedings Volume ab-cd (The American Society of Mechanical Engineers, XYZ City, 1999) xyz-hkl, presented at the 1999 International Mechanical Engineering Congress and Exposition, Symposium on, Nashville, Tennessee, November 14-19, 1999, UCRL-JC-133146

9. J.D. Morse, A.F. Jankowski, R.T. Graff, and J.P. Hayes, "A Novel Proton Exchange Membrane Thin-Film Fuel Cell for Micro-Scale Energy Conversion", Journal of Vacuum Science and Technology (accepted for publication), presented at the American vacuum Society 46th 
International Symposium on Vacuum, Thin Films, Surfaces/Interfaces, and Processing, Seattle, Washington, October 25-29, 1999, UCRL-JC-134243 